\title{
Microalbuminuria as a potential novel cardiovascular biomarker in patients with COPD
}

\author{
Ciro Casanova ${ }^{1,2}$ and Bartolome R. Celli ${ }^{3}$
}

Affiliations: 'Pulmonary Dept, Hospital Universitario La Candelaria, Tenerife, ${ }^{2}$ Respiratory Research Unit, Hospital Universitario La Candelaria, Tenerife, Spain. ${ }^{3}$ Brigham and Women's Hospital, Harvard Medical School, Boston, MA, USA.

Correspondence: C. Casanova, Respiratory Research Unit, Pulmonary Dept, Hospital Universitario La Candelaria, Carretera del Rosario no. 145, 38010 Santa Cruz de Tenerife, Spain.

E-mail: casanovacirolgmail.com

-

@ERSpublications

Microalbuminuria is a simple biomarker that identifies COPD patients at increased cardiovascular risk http://ow.ly/tdIAB

Chronic obstructive pulmonary disease (COPD) is now recognised as the third cause of death in the world [1]. Patients with COPD are more likely to have pre-existing cardiovascular disease (CVD) and are at high risk of acute events, hospitalisations and death from $\operatorname{CVD}[2,3]$. Furthermore, this strong association is independent of the degree of airflow limitation. Because of this, the Global Initiative for Chronic Obstructive Lung Disease initiative recognises CVD as the most important disease coexisting with COPD and suggests it should be routinely looked for, but makes no recommendation on how to do it [4].

Over the past two decades, interest in CVD prevention has expanded and now promotes not only primary prevention, but also identification of factors that could help clarify CVD pathophysiology, offer targets for intervention or lead to improved risk stratification beyond that allowed by the Framingham equations [5]. Currently, only a few biomarkers have been accepted as being clinically useful [6]. In this regard, the recent consensus of the American College of Cardiology/American Heart Association recognises family history as being useful and haemoglobin Alc measurement as reasonable in all adults. They also categorise microalbuminuria $(\mathrm{MAB})$ assessment as reasonable in adults with hypertension or diabetes [7].

The discovery of novel "biomarkers" that could help identify cardiovascular risk in patients with COPD could help personalise therapy for that particular phenotype. To be clinically useful, the biomarker should be inexpensive, noninvasive and easily measurable. Therefore, $\mathrm{MAB}$ could be a promising biomarker to identify patients with COPD at increased risk for poor cardiovascular outcomes. The presence of MAB is consistently associated with arterial stiffness assessed by pulse wave velocity and worse cardiovascular outcomes in patients with diabetes, hypertension and, importantly, in the general population [8-10]. MAB has been shown to have a stronger association with cardiovascular events and death than C-reactive protein [11], and is thought to reflect a state of generalised endothelial dysfunction.

The limited number of studies that have investigated the presence of MAB in patients with COPD have reported a high prevalence in patients during acute exacerbations [12-14] and, importantly, also in stable state $[15,16]$. Several authors have shown that after adjusting for smoking and independent of the presence of diabetes and hypertension, the prevalence is $\sim 25 \%$ of patients with stable COPD $[15,16]$.

In this issue of European Respiratory Journal (ERJ), ROMUNDSTAD et al. [17] confirm this data in a large population-based study. A total of 3129 subjects, aged $\geqslant 20$ years, with spirometry and morning urine

Received: Jan 222014 | Accepted: Jan 232014

Conflict of interest: None declared.

Copyright @ERS 2014 
samples for MAB analysis were included in the main analysis. $136(\sim 22 \%)$ of the 631 patients had COPD and $\mathrm{MAB}$, defined as an albumin/creatinine ratio (urine albumin $(\mathrm{mg})) /($ urine creatinine $(\mathrm{mmol})$ ) between 2.5 and $30 \mathrm{mg} \cdot \mathrm{mmol}^{-1}$. In this study, $\mathrm{MAB}$ was evaluated in three morning urine samples and the final data was defined as the mean of three albumin/creatinine ratio measurements, rendering more precision to the final estimate.

In the Nord-Trøndelag Health Study (HUNT) cohort in 2003, ROMUNDSTAD et al. [18] observed that the presence of MAB was associated with a two-fold increased risk of all-cause mortality in healthy individuals without diabetes or hypertension. In this issue of the ERJ, they expanded the analysis to a group of patients who had also undergone spirometry. For the first time, they showed a positive association between MAB and all-cause mortality [17]. Although others factors such as exacerbations or symptoms were not measured and residual confounding are possible, the results were based on a large cohort with long-term follow-up (mean 12 years) and a high number of deaths (319 subjects with COPD died). They also observed an association between $\mathrm{MAB}$ and the level of airways obstruction, similar to that reported previously in a clinical study [16]. However, the HUNT study did not evaluate other variables such as arterial oxygen tension $\left(\mathrm{PaO}_{2}\right)$, which was the factor most strongly associated with MAB in two previous studies $[15,16]$.

The association with all-cause mortality was significantly increased, even after excluding the presence of CVD at baseline. However, cardiovascular mortality was not significantly increased in this study. This suggests that $\mathrm{MAB}$ could reflect a low-grade systemic inflammation, independent of the process of atherosclerosis. However, it is possible that the difficulty in ascertaining accurate cause of death in COPD patients (information was from the Norway Cause of Death Registry and classified according the International Statistical Classification of Diseases) could explain the lack of association between MAB with cardiovascular death in this study.

Little is known about the factors that determine the onset of proteinuria and even less is known about the relationship between $\mathrm{MAB}$ and the pathogenesis of COPD. In the general population, the systolic blood pressure and fasting glucose appear to be the most important factors related to $\mathrm{MAB}$, through their direct effect on the glomerular intra-renal pressure or the stimulation of the renin-angiotensin-aldosterone system [19]. Inflammation, endothelial dysfunction and thrombogenic factors have been implicated as potential mechanisms underlying the relationship between proteinuria and cardiovascular disease [20]. Indeed, circulating von Willebrand factor, soluble vascular cell adhesion molecule, fibrinogen and tissue plasminogen activator have been found to correlate with urinary albumin excretion. More recently, MAB has been associated with novel biomarkers (high-sensitivity troponin T, C-reactive protein and vascular endothelial growth factor) in addition to classical cardiovascular risk factors (HbAlc, coronary calcium and carotid intima-media thickness). However, the majority of studies demonstrating relationships between proteinuria and cardiovascular risk factors are cross-sectional and so inference regarding causality cannot be drawn. Unfortunately, biomarkers were not measured in the HUNT study, so the question remains unanswered.

The effect of the tissue hypoxia on the kidney could be another possible cause of MAB. In fact, it could explain the increase of $\mathrm{MAB}$ prevalence that has been reported in subjects living at high altitude even with preserved glomerular filtration rate [21]. In fact, in two recently published studies [15, 16], the $\mathrm{PaO}_{2}$ was the main factor inversely associated with $\mathrm{MAB}$. Interestingly, no previous studies have considered the possible association between $\mathrm{PaO}_{2}$ and MAB in population cohorts or in studies in patients with diabetes or hypertension.

Given that the presence of MAB is independently associated with increased risk of death, it could be a therapeutic target for risk reduction. However, studies of earlier and aggressive intervention with reninangiotensin-aldosterone system blocking agents have demonstrated a reduction in proteinuria, but this has not yet translated into reduction in hard cardiovascular end-points. Furthermore, these studies have also reported a greater degree of side-effects and adverse events [22], so careful studies are needed to clarify the mechanism by which MAB occurs in general and in patients with COPD in particular, and how its management may influence ultimate outcomes.

In summary, the presence of MAB is increased in patients with stable COPD and is mainly associated with hypoxaemia. As a novel and important finding in this issue of ERJ, MAB is associated with all-cause mortality in this population. In theory, MAB could be a promising biomarker to identify patients with COPD at increased cardiovascular risk. More carefully obtained longitudinal data of MAB and its relationship with others biomarkers and cardiovascular risk factors are urgently needed. Finally, welldesigned interventional trials that can support a potential role of MAB as a target in the management of patients with COPD should be considered.

\section{References}

1 Lozano R, Naghavi M, Foreman K, et al. Global and regional mortality from 235 causes of death for 20 age groups in 1990 and 2010: a systematic analysis for the Global Burden of Disease Study 2010. Lancet 2012; 380: 2095-2128. 

Crit Care Med 2002; 166: 333-339.

3 Calverley PM, Anderson JA, Celli B, et al. Salmeterol and fluticasone propionate and survival in chronic obstructive pulmonary disease. N Engl J Med 2007; 356: 775-789.

4 Vestbo J, Hurd SS, Agusti AG, et al. Global strategy for the diagnosis, management and prevention of chronic obstructive pulmonary disease. NHLBI/WHO Global Initiative for chronic obstructive pulmonary disease (GOLD). Workshop summary. Am J Respir Crit Care Med 2013; 187: 347-365.

5 Wilson PW, D'Agostino RB, Levy D, et al. Prediction of coronary heart disease using risk factor categories. Circulation 1998; 97: 1837-1847.

6 Folsom AR. Classical and novel biomarkers for cardiovascular risk prediction in the United States. J Epidemiol 2013; 23: $158-162$.

7 Greenland P, Alpert JS, Beller GA, et al. 2010 ACCF/AHA guideline for assessment of cardiovascular risk in asymptomatic adults: Executive summary. A report of the American College of Cardiology Foundation/American Heart Association Task Force on Practice Guidelines. Circulation 2010; 122: 2748-2764.

8 Papaioannou GI, Seip RL, Grey NJ, et al. Brachial artery reactivity in asymptomatic patients with type 2 diabetes mellitus and microalbuminuria. Am J Cardiol 2004; 94: 294-299.

9 Mule G, Cottone S, Vadala A, et al. Relationship between albumin excretion rate and aortic stiffness in untreated essential hypertensive patients. J Intern Med 2004; 256: 22-29.

10 Kohara K, Tabara Y, Tachibana R, et al. Microalbuminuria and arterial stiffness in a general population: the Shimanami Health Promoting Program (J-SHIPP) study. Hypertens Res 2004; 27: 471-477.

11 Kistorp C, Raymond D, Pedersen F, et al. N-terminal pro-brain natriuretic peptide C-reactive protein, and urinary albumin levels as predictors of mortality and cardiovascular events in older adults. JAMA 2005; 293: $1609-1616$.

12 Komurcuoglu A, Kalenci S, Kalenci D, et al. Microalbuminuria in chronic obstructive pulmonary disease. Monaldi Arch Chest Dis 2003; 59: 269-272.

13 Cogo A, Ciaccia A, Legorini C, et al. Proteinuria in COPD patients with and without respiratory failure. Chest 2003; 123: 652-653.

14 Polatli M, Cakir Q, Cildag O, et al. Microalbuminuria, von Willebrand factor and fibrinogen levels as markers of the severity in COPD exacerbation. J Thromb Thrombolysis 2008; 26: 97-102.

15 Casanova C, de Torres JP, Navarro J, et al. Microalbuminuria and hypoxia in patients with chronic obstructive pulmonary disease. Am J Respir Crit Care Med 2010; 182: 1004-1010.

16 Bulcun E, Ekici M, Ekici A, et al. Microalbuminuria in chronic obstructive pulmonary disease. COPD 2013; 10: $186-192$.

17 Romundstad S, Naustdal T, Romundstad PR, et al. COPD and microalbuminuria, a 12-year follow-up study. Eur Respir J 2014; 43: 1042-1050.

18 Romundstad S, Holmen J, Kvenid K, et al. Microalbuminuria and all-cause mortality in 2,089 apparently healthy individuals: a 4.4 year follow-up study. The Nord-Trøndelag Health Study (HUNT), Norway. Am J Kidney Dis 2003; 42: 466-473.

19 Palatini P, Mormino P, Dorigatti F, et al. Glomerular hyperfiltration predicts the development of microalbuminuria in stage 1 hypertension: the HARVEST. Kidney Int 2006; 70: 578-584.

20 Currie G, Delles C. Proteinuria and its relation to cardiovascular disease. Int J Nephrol Renovasc Dis 2013; 7: 13-24.

21 Hurtado A, Escudero E, Pando J, et al. Cardiovascular and renal effects of chronic exposure to high altitude. Nephrol Dial Transplant 2012; 27: 11-16.

22 ONTARGET Investigators. Telmisartan, ramipril, or both in patients at high risk for vascular events. $N$ Engl J Med 2008; 358: 1547-1559. 